\title{
¿Vivas nos queremos! Un análisis de sentencias sobre los femicidios de 2014 en la provincia de Córdoba
}

\section{We want us alive! An analysis of judgments about the femicides of 2014 in the province of Cordoba}

\section{Artaza, Carolina; Gisella Jacqueline Vogel Sánchez, Gisella ${ }^{1}$}

Resumen. El presente trabajo tiene el objeto de identificar, a partir de sentencias judiciales, patrones que caracterizaron al fenómeno de los femicidios en la provincia de Córdoba en el año 2014. Para ello, se realiza un análisis cualitativo de los discursos de diversos actores presentes en el texto de las sentencias, desde un enfoque de género. En el artículo se construyen categorías que explican y problematizan esos patrones, evidenciando el modo en que los mismos dan cuenta de un entramado socio-cultural subyacente que los sustenta y les da lugar. En las mismas se abordan aspectos múltiples y multidimensionales, que van desde el hecho concreto que desencadenó el femicidio hasta contextos y factores previos, e implicancias posteriores al mismo.

Palabras clave: violencia de género - femicidios - sentencias judiciales - metodología cualitativa - patriarcado

\begin{abstract}
The present paper has the purpose of identifying, from judicial sentences, patterns that have characterized the phenomenon of femicides in the province of Córdoba during 2014. From a gender perspective, a qualitative analysis of the speeches of various actors will be

\footnotetext{
${ }^{1}$ Artaza, Carolina. Licenciada en Ciencia Política. Facultad de Ciencia Política y Relaciones Internacionales. Universidad Católica de Córdoba. Córdoba, Argentina. Correo electrónico: carolinaartaza10@ gmail.com.

Gisella Jacqueline Vogel Sánchez, Gisella. Licenciada en Ciencia Política. Licenciada en Relaciones Internacionales. Facultad de Ciencia Política y Relaciones Internacionales. Universidad Católica de Córdoba. Becaria DAAD, Göttingen, Alemania. Córdoba, Argentina. Correo electrónico: gisella.vogel@ gmail.com
}

Debates actuales en Psicología y Sociedad. ISSN en línea: 2591-524X

Año II, № 2, 2019. Pág. 60-89.

DOI: 10.22529/daps.2019.2(2)05 / Recibido: 12-8-2018 / Aprobado: 19-12-2019.

Artículo publicado bajo Licencia Creative Commons Atribución-NoComercial-SinDerivar.

(c) Universidad Católica de Córdoba. 
carried out. In this article, categories are constructed trying to explain and problematize repetitive behavior patterns, providing evidence for the way in which they account for a sociocultural understanding that sustains them and gives them place. These patterns are aspects that are addressed multiple and multidimensional, ranging from the concrete facts that triggered the femicide up to previous contexts and factors, and later implications.

Keywords: gender violence - femicides - court decisions - qualitative methodology patriarchy 


\title{
Introducción
}

\begin{abstract}
"Hay criminales que proclaman tan campantes 'la maté porque era mía', así no más, como si fuera cosa de sentido común y justo de toda justicia y derecho de propiedad privada, que hace al hombre dueño de la mujer. Pero ninguno, ninguno, ni el más macho de los supermachos tiene la valentía de confesar 'la maté por miedo', porque al fin y al cabo el miedo de la mujer a la violencia del hombre es el espejo del miedo del hombre a la mujer sin miedo"
\end{abstract}

Eduardo Galeano

La violencia contra las mujeres ha sido históricamente fruto de la sociedad patriarcal en la que nos encontramos inmersos y su ejercicio siempre ha estado vinculado de manera directa con el papel que las mujeres han jugado tradicionalmente en la sociedad. Estas acciones contra las mujeres tienen muchas caras y manifestaciones, así como orígenes y consecuencias, pero de manera generalizada tienden a reproducirse, agudizarse y hasta combinarse con otros tipos de violencia. En palabras de Francesca Gargallo (2012):

La violación más frecuente a los derechos humanos de las mujeres es relativa a la violencia que sufrimos en los diferentes ámbitos de la vida y que se manifiesta en la "privatización" — es decir, la extrapolación de lo político, social y comunitario, para rebajar su contenido- de la violencia sexual, el acoso y la violencia intra y extra doméstica.(...) La violencia contra las mujeres resume todos los aspectos de la violencia social, aunque reviste características especiales de denigración del cuerpo y de las formas de vida de las víctimas. (p. 23)

En relación a este planteo, es posible afirmar que el ejercicio de violencia no se limita a aquella que se puede observar, si no que implican un continuum que va desde un mundo de situaciones que pueden llegar a ser imperceptibles para los externos y hasta para las propias mujeres, como es el caso de la violencia simbólica y los micro-machismos, pasando por la violencia psicológica y económica, agudizándose consecuentemente con la física y sexual, y teniendo su corolario en la expresión máxima de violencia: el femicidio. De esta forma, el constante ejercicio de esta violencia se presenta como un "castigo" para aquellas que osaron rebelarse, defenderse y emanciparse en contra los mandatos sociales y las estructuras de poder impuestas o por el simple hecho de ser mujer en una sociedad androcéntrica y patriarcal.

En este sentido el femicidio, expresión máxima de la violencia contra la mujer, es definido por la Corte Suprema de Justicia de la Nación como: 
la muerte violenta de mujeres por razones de género, ya sea que tenga lugar dentro de la familia, unidad doméstica o en cualquier otra relación interpersonal; en la comunidad, por parte de cualquier persona, o que sea perpetrada o tolerada por el Estado y sus agentes, por acción u omisión. (CSJN, 2015, p. 1).

Dicha definición resulta pertinente como medio para categorizar y condenar estos crímenes, pero no se debe dejar de lado el carácter social y cultural de los femicidios, y que estas expresiones de violencia son frutos de la sociedad actual. En este sentido

los asesinatos de mujeres están también íntimamente relacionados en proporción directa al grado de tolerancia que cada sociedad manifieste en torno a los mismos y a su nivel de violencia (...) Estos asesinatos sexuales son producto de la cultura dominante. Es la expresión última de una sexualidad que define el sexo como una forma de dominación/poder. Es una forma de terror que construye y mantiene la supremacía masculina. (Fragoso Monárrez, 2000, pp. 5-7)

Es por ello que para evitar llevar a cabo un análisis simplista y sesgado del femicidio resulta necesario comprender que, dicho fenómeno, está regido por una lógica asociada a relaciones de poder opresivas entre varones y mujeres, y en la cuales las mujeres que se encuentran inmersas en relaciones violentas o que quieren concluir su vínculo con compañeros violentos son las que mayor riesgo tienen de padecerlo.

En relación a lo expuesto resulta de gran relevancia mencionar otros condicionantes que se asocian a la violencia que sufren las mujeres y a sus distintas manifestaciones, por ejemplo: las condiciones de pobreza, la exclusión social generalizada, las preferencias sexuales u otros tipos de conducta que ponen en tensión y cuestionan las normas de comportamiento socialmente reconocidas y de adscripción al rol tradicional de la mujer. Pero, sea cual sea el caso, la causa fundamental se asocia directamente a la condición subordinada de género de las mujeres en el sistema patriarcal. El femicidio es, en consecuencia, un fenómeno absolutamente político y social, que sólo es posible debido a que existen dispositivos y lógicas culturales que han institucionalizado y reproducen relaciones de poder opresivas entre los sexos (Aguilar, 2005).

En una sociedad signada por estas relaciones de género que denotan estructuras de poder, los femicidios se han vuelto moneda corriente. Según datos del Registro Nacional de Femicidios elaborado por la Corte Suprema de Justicia la Nación (2015) solamente en 2015 
existieron 235 víctimas de femicidio. En promedio, una mujer muere en Argentina cada 37 horas víctima de la violencia de género.

Ante semejantes cifras cabe preguntar ¿Por qué, a pesar de la creación de la figura penal de Femicidio, la sanción de normativas como la ley nacional $\mathrm{N}^{\circ} 26.485$ de Protección Integral a las Mujeres y la vigencia de instrumentos de carácter internacional como son la Convención sobre la eliminación de Todas las Formas de Discriminación contra la Mujer (CEDAW) y la Convención Interamericana para Prevenir, Sancionar y Erradicar la Violencia contra la mujer (Convención de Belem Do Para) la problemática, lejos de menguar, se acrecienta y agudiza día a día?

En relación a lo expuesto es necesario analizar el rol que el derecho y los encargados de impartir justicia juegan en la configuración de las relaciones de poder en las que se engendra esta violencia. En este sentido es posible afirmar que las reglas del derecho, permean, permiten y condicionan ciertas prácticas y relaciones de poder, que a su vez producen discursos de verdad. En consecuencia el derecho “(...) ha sido el modo de representación principal del poder” (Foucault, 1979, p.170).

En este sentido, cobra relevancia la sentencia judicial como objeto de estudio. Esto se debe a que una sentencia genera efectos de verdad en tanto sus argumentos son retomados una y otra vez por actores diversos ante situaciones diversas (producciones académicas, fallos posteriores, recursos periodísticos). Además de los efectos condenatorios o absolutorios que siguen a la sentencia, la misma toma ciertos recursos, argumentos y cosmovisiones como válidos y rechaza otros, generando efectos de verdad y reproduciendo relaciones de poder.

Es a raíz de esto que se propone, llevando a cabo un análisis crítico del discurso, analizar las sentencias sobre femicidios cometidos en 2014 en la provincia de Córdoba, con el objetivo de detectar parámetros comunes y categorías que visibilicen la violencia de género y las estructuras de dominación patriarcal. Para este análisis, serán desarrolladas ampliamente nociones centrales como: género, patriarcado, estereotipos y roles de género. Así también el concepto mismo de femicidio, en su carácter jurídico, social y cultural y el rol que el derecho juega como constructor y reproductor de las condiciones de dominación y opresión. Posteriormente se desarrollarán las categorías elaboradas a partir de las lecturas y su aplicación a las sentencias, para culminar en reflexiones y valoraciones finales. 


\section{Marco conceptual}

En el presente apartado se delinean algunos conceptos y relaciones entre los mismos que resultan claves para el posterior análisis, enmarcados en una epistemología postestructuralista.

Uno de los conceptos transversales a todo el escrito es la categoría "género", esgrimida en primera instancia por el feminismo anglosajón de los setenta, en torno a la cual han girado diversas disputas y no hay acuerdos unánimes. Siguiendo a Butler (2001), el género es una construcción de la subjetividad que es resultado de la performatividad de una repetición ritualizada de actos que terminan por naturalizarse y producir la ilusión de una sustancia, de una esencia. Así, las características entendidas como femeninas son adquiridas a través de un proceso cultural, social y político, y no por la naturaleza del sexo biológico.

En consecuencia, los diversos modos de comportarse, sentir y pensar pueden ser atribuidos a construcciones sociales $y$ familiares asignadas a varones y mujeres, configurándose de esta manera lo que se entiende por la masculinidad y la feminidad. Por lo tanto, es el condicionamiento social el que induce a los varones, desde su infancia, a desarrollar actitudes de superioridad, mientras que a las mujeres las restringe y limita a la pasividad, la sumisión y el ocultamiento de las capacidades que no entren en la categoría de "lo femenino" (Vélez Bautista, 2008).

La teoría de género hace referencia a las significaciones atribuidas al hecho de ser varón o ser mujer en cada cultura, y hacen visible que las jerarquías no son naturales sino que han sido construidas mediante un proceso histórico-social en el que subyacen las relaciones de poder. En tal sentido, casi todas las culturas occidentales elaboran nociones de masculinidad y feminidad bajo una lógica dualista y de oposiciones binarias, en los términos de "mujerhombre, naturaleza-cultura, privado-público, emocionalidad-racionalidad”, estableciéndose, casi por generalidad, a los sexos en una gradación en escala (Vélez Bautista, 2008).

Es por ello que se define a los varones en términos de su status o rol social de guerrero, cazador, jefe, sostén del hogar, etc.; mientras que la mujer es definida, en términos androcéntricos y en relación al varón, como esposa de, hija de, hermana de, madre de, etc. A raíz de esto, las mujeres terminan siendo subordinadas y estigmatizadas, como consecuencia del proceso por el cual son tratadas como objeto que impide a las mismas ser consideradas sujetos plenos de derecho (Vélez Bautista, 2008).

En la mayoría de los casos, de esta situación se deriva la perpetuación de estereotipos de género culturales que asignan, tanto al varón como a la mujer, características y roles 
¡Vivas nos queremos!

Un análisis de sentencias sobre los femicidios de 2014 en la provincia de Córdoba

naturalizados que delimitan los deberes y obligaciones de ambos, ubicando a la mujer como propia del espacio doméstico y al hombre como actor de la esfera pública. Estos estereotipos pueden verse reflejados en prácticas de autoridades jurídicas, y oscilan entre no creer a las víctimas (asignándoles el adjetivo de mujer mendaz, instrumental o fabuladora) y castigarlas por apartarse del rol social asignado (vale decir, del estereotipo de la mujer honesta y mujer co-responsable) o de lo que se espera de una víctima "real" de violencia de género (Asensio, 2010).

En este sistema machista-patriarcal que se renueva y reproduce constantemente las mujeres han sido históricamente víctimas de violencia de distinta índole: física, cultural, psicológica, económica, sexual y su manifestación más extrema: el femicidio. Éste último es entendido como

el asesinato de mujeres por el hecho de serlo; es decir, por su condición de género. Está vinculado a las relaciones de inequidad y exclusión que vivimos las mujeres en la sociedad y se manifiesta en el contexto de la violencia sexista (...) No es un asunto privado, sino un fenómeno histórico, de orden social, que ocurre para perpetuar el poder masculino en las sociedades patriarcales. (Aguilar, 2005, p. 2)

Según la misma autora, el femicidio es la manifestación más extrema de un continuum de violencia al que las mujeres han estado históricamente sometidas; siendo la violencia de género el elemento central para comprender la condición social de las mismas. La presencia o amenaza real de violencia cotidiana y de femicidio ilustran cómo la opresión y la desigualdad colocan a las mujeres en una posición vulnerable (Aguilar, 2005).

No obstante, aún existen muchos sectores que tienden a desconocer a la violencia sexista como el origen indiscutible del femicidio, y atribuyen sus causas a la violencia generalizada en la sociedad; catalogando a estos asesinados como "normales" e indiferenciables de cualquier otro, perdiendo de vista que el femicidio sólo es factible debido a que existen dispositivos y lógicas culturales que han institucionalizado y reproducen relaciones de poder opresivas entre los $\operatorname{sexos}^{2}$ (Aguilar, 2005).

En materia jurídica se ha desarrollado un conjunto de normas, estándares y principios para alcanzar la plena vigencia de los derechos de las mujeres. Estos instrumentos

\footnotetext{
${ }^{2}$ Con ello no se niega que la violencia contra las mujeres tenga múltiples causas siendo una de fundamentales el género.
} 
internacionales, como la CEDAW o la Convención de Belém do Pará son de carácter vinculante para aquellos Estados que los han ratificado.

En lo que hace a la legislación nacional, el femicidio se ha constituido como una figura en el Código Penal Argentino. La tipificación de la figura tuvo lugar tras un ajetreado debate $-\mathrm{y}$ no carente de cuestionamientos- al interior de ambas Cámaras del Congreso Argentino. Como lo apunta Buompadre (2013) se trata de un tipo agravado de homicidio, cualificado por el género del autor, que exige la concurrencia de las siguientes condiciones:

a) Que el autor del homicidio sea un hombre

b) Que la víctima sea una mujer

c) Que el agresor haya matado a la víctima "por ser mujer" (pertenencia al género femenino), y

d) Que el asesinato se haya perpetrado en un contexto de violencia de género.

Una de las grandes acusaciones que se realizaba a tal figura era el ir en contra de la "igualdad ante la ley" de todos reconocido por el art. 19 de la CN, y carecer de fundamento. En respuesta a ello, cabe señalar que el fundamento de la mayor penalidad se encuentra

en la condición del sujeto pasivo y en las circunstancias especiales de su comisión: violencia ejercida en un contexto de género. De aquí que el asesinato de cualquier mujer, en cualquier circunstancia, no implica siempre y en todo caso femicidio, sino sólo aquélla muerte provocada en un ámbito situacional específico, que es aquél en el que existe una situación de subordinación y sometimiento de la mujer hacia el varón, basada en una relación desigual de poder. (Buompadre, 2013, p. 31)

Vale decir, tiene en cuenta el contexto patriarcal al que se ha hecho referencia previamente. Es este contexto el que marca la diferencia con otros tipos de delito, en particular con el homicidio. Por tanto, en situaciones de violencia de género no se puede tratar igual a los desiguales, pues ello sólo perpetuaría la desigualdad.

Ya algunas décadas atrás, diversas perspectivas feministas habían señalado que el derecho puede ser "a la vez, un instrumento de reforma social y una fuerza que contribuye a mantener a las mujeres en su sitio" (Censori, 2016, p.6) y que es un espacio importante para la lucha femenina. Es decir, no se descarta su incidencia en la praxis, pues las reglas del derecho, permean, permiten y condicionan ciertas prácticas y relaciones de poder, que a su 
¡Vivas nos queremos!

Un análisis de sentencias sobre los femicidios de 2014 en la provincia de Córdoba

vez producen discursos de verdad. El derecho, de esta manera, tiene un impacto directo sobre la población que se encuentra bajo sus efectos (Foucault, p. 1979).

El derecho es un discurso, y los discursos, siguiendo a Foucault (1979), no son en sí mismos ni verdaderos ni falsos. Detrás de todo conocimiento, y detrás de todo el derecho pues el derecho es también un conocimiento- lo que está siempre en cuestión es la lucha por el poder. Foucault refiere a ello como un triángulo entre poder, derecho y verdad: "por un lado las reglas del derecho que delimitan formalmente el poder, por otro los efectos de verdad que éste poder produce, transmite y que a su vez reproducen ese poder" (p. 139).

En este sentido, el binomio saber-poder crea en toda sociedad una política general de verdad que se encarga de distinguir los enunciados falsos de los verdaderos, de sancionar los discursos alternativos y de definir las técnicas y procedimientos adecuados para la obtención de la verdad que interesa al poder (Foucault, 1979).

No perdamos de vista que el derecho $-\mathrm{y}$ el derecho penal en especial- es violencia institucionalizada, regulada, formalizada. Lo que distingue a las normas jurídicas de otras normas es que cuentan con un aparato estatal destinado a garantizar su cumplimiento y además con una sanción, en caso que no se cumplan; su violación acarrea una sanción externa e institucionalizada (Bobbio, 1994). No obstante el derecho, como dispositivo de poder, no se agota en la sanción.

El dispositivo judicial es normalizador y disciplinario. Los aparatos disciplinarios jerarquizan unos individuos en relación con los otros, las "buenas" y las "malas" personas; mientras el poder de la normalización obliga a la búsqueda de la homogeneidad. La sanción busca calibrar a los individuos en "verdad" (Foucault, 1975). Sus discursos generan efectos de verdad que dan lugar a sometimientos polimorfos.

A través de la teorización precedente, el presente escrito busca poner en evidencia que el corpus del derecho, su permanente construcción y sus consecuencias, son considerablemente más abarcativos de lo que prescribieron las teorías positivistas clásicas y muchos juristas en el siglo XXI.

\section{Metodología de investigación}

En el presente trabajo se ha utilizado una metodología de investigación cualitativa, haciendo uso del análisis de discurso, para algunos de los patrones que caracterizaron a los femicidios de la provincia de Córdoba en el año 2014. Dichos patrones se tornan visibles en el discurso de las sentencias judiciales, y los mismos abarcan aspectos más amplios que la 
sentencia misma. Extraer estos discursos de una sentencia nos permite analizar y contextualizar una polifonía de voces: testimonios de amigos y familiares de las víctimas y los victimarios, de las mismas víctimas en denuncias previas, como también de abogados, defensores y jueces.

El abordaje adoptado se abre al trabajo de campo no en búsqueda de la comprobación de hipótesis previas del investigador, sino del dato emergente. Se eligió trabajar los casos ocurridos en el año 2014 porque todos han tenido ya resolución judicial -exceptuando aquellos en los cuales el victimario se suicidó y no se debió dictar sentencia- y porque, además de ser recientes, se trata de un buen número de casos (se analizaron 11 sentencias) ${ }^{3}$ que posibilita la identificación de algunos patrones. A su vez, retomar estos relatos del texto de las sentencias es una forma de reconstruir discursivamente hechos y contextos pasados, a los cuales sería considerablemente difícil acceder de otra manera.

Analizar discursos resulta crucial en tanto el discurso es una de las formas en que las ideologías se reproducen. En palabras de Van Dijk (1999)

Si queremos saber que apariencia tienen las ideologías, como funcionan y como se crean, cambian y reproducen, necesitamos observar detalladamente sus manifestaciones discursivas (p. 19). A diferencia de la mayor parte de las otras prácticas sociales (...) diversas propiedades del texto y la conversación les permiten a los miembros sociales expresar o formular concretamente creencias ideológicas abstractas, o cualquier otra opinión relacionada con esas ideologías. (...) el discurso no solo exhibe indirectamente la ideología, sino que también formula explícitamente creencias ideológicas de manera directa. (pp. 244-245)

En cuanto el discurso posee un rol primordial sobre la producción o reproducción del abuso de poder o dominación, y en el establecimiento de una "hegemonía de pensamiento", tiene un importante carácter social. De aquí surge que busquemos constantemente relacionar a los discursos con el entramado socio-cultural del cual forman parte y en el cual toman parte, como modo de explicar la iteración de ciertos rasgos discursivos en los distintos casos analizados.

El núcleo central de la investigación es poner en evidencia "cómo el discurso contribuye a la reproducción de la desigualdad y la injusticia determinando quienes tienen acceso a estructuras discursivas y de comunicación aceptables y legitimadas por la

\footnotetext{
${ }^{3}$ Es decir todas las sentencias que tenía disponibles en ese año en la Oficina de la Mujer, Tribunal Superior de Justicia de la Provincia de Córdoba.
}

69 | Debates actuales en Psicología y Sociedad. Año II, № 2, 2019. Pág. 60-89. 
¡Vivas nos queremos!

Un análisis de sentencias sobre los femicidios de 2014 en la provincia de Córdoba

sociedad" (Van Dijk, 1994, p. 6). En esta reproducción tiene un lugar central el poder, entendido según Van Dijk (2004) como un mecanismo de control mental, en el cual ciertos hablantes (individuos, grupos o instituciones) a través de sus discursos persuaden a determinados grupos de la sociedad o a la sociedad en su conjunto.

Para elucidar ideologías que están detrás de los discursos analizados, se hace énfasis en visibilizar subjetivemas (que enuncian la posición subjetiva explícita de los enunciadores en la conceptualización de los mundos) modalizadores (a través de los cuales los enunciadores se sitúan en el mensaje) y polarizaciones nosotros-ellos, que se encuentran en las sentencias. Por ello se retoman en cada apartado del análisis ejemplos textuales de las sentencias, ya que en la representación y definición del mundo que lo rodea, quien realiza enunciaciones y descripciones -aún sin quererlo- asume y deja traslucir una posición subjetiva explícita, que no se haría evidente a través de un análisis cuantitativo.

\section{Análisis de sentencias}

A raíz de la lectura y el análisis de sentencias se han elaborado diversas categorías, interrelacionadas y conectadas entre sí, con la intención de brindar herramientas útiles para comprender y explicar el fenómeno del femicidio. Es necesario aclarar que estas categorías, elaboradas por las autoras, lejos están de ser conceptos únicos, universales y totalizadores.

No obstante, conocer los patrones que caracterizan a los femicidios, permite trabajar sobre los mismos, abriendo algunas reflexiones en torno a las políticas estatales de prevención y protección de las mujeres. Tan sólo si se realiza un buen diagnóstico de la realidad del fenómeno, las medidas tomadas a posteriori podrán ser más adecuadas.

He aquí un esbozo que ha de servir como diagnóstico. Lo fructífero de este análisis se encuentra precisamente en la presencia, continuidad, persistencia y transversalidad de estas categorías en casos judiciales de características diferentes, ya sea por la naturaleza del vínculo, las características personales de los involucrados, el nivel socio-económico, etc.

El siguiente desarrollo se estructurará en apartados, cada uno haciendo foco en alguno de los patrones observados, utilizando fragmentos de las sentencias para ejemplificar las categorías propuestas.

\section{Datos socio-demográficos}

En primera instancia se podría llevar a cabo un análisis socio-demográfico de los imputados. En este sentido se observa que todos son varones, comprendidos en una franja 
etárea entre 33 y 55 años, lo cuales mantenían algún tipo de vínculo amoroso con las víctimas. En relación al nivel socio-económico no se puede inferir correspondencia entre dicha condición y los crímenes, dada las disimilitudes en el poder adquisitivo que presentaron los imputados. Con esto se busca recalcar que no es posible establecer una relación entre el nivel socio-económico y los femicidio.

Por su parte el vínculo que unía a la víctima y el victimario osciló entre pareja, expareja, amante y concubino, es por ello que aquí sí se podría establecer una relación entre el tipo de vínculo y la violencia que las mujeres sufrían en el seno de estas relaciones. A partir de ello se pueden desmembrar y desarrollar diversas categorías que permean estos vínculos y las relaciones de violencia entre varones y mujeres en la sociedad machista y patriarcal contemporánea.

\section{Violencia previa y contextos afectivos}

Los antecedentes de violencia física y psicológica, en todas las sentencias, son claros y evidentes. Los indicios de violencia previa, constante y prolongada dejan en claro que la violencia de género se cierne en el establecimiento de un vínculo de dependencia emocional y posesión, difícil de romper; pues se basa en una dinámica que mantiene atrapadas psicológicamente a las mujeres maltratadas, despojándolas de su seguridad, autonomía y confianza (La Nación, 2015; Gobierno de México, 2016).

Bastante ilustrativa resulta este fragmento de la sentencia de Orellano, en la cual se evidencia el contexto de maltratos y el ciclo de violencia en que la víctima se encontraba inmersa, y del cual le fue imposible salir:

“(...) Acción homicida que se produce conforme a lo relatado teniendo a un hombre como victimario ejerciendo supremacía de poder y a una mujer vulnerable como víctima, mediando las siguientes circunstancias de violencia de género, a saber: la obligaba a tener relaciones sexuales utilizando chantaje económico, provocando temor en la Sra. M. Repudiaba, denostaba y obstaculizaba las tareas religiosas que realizaba la víctima, pese a haber decidido culminar la relación de pareja le era impedido por Orellano, por falta de recursos económicos de la víctima, situación conocida y aprovechada por el imputado. La denostaba en público y en privado discriminándola por su edad tratándola de vieja, en otras palabras, ejercía violencia de género del tipo sexual, económica y psicológica ${ }^{4}$. Estos

\footnotetext{
${ }^{4}$ El destacado es de las autoras.
}

71 Debates actuales en Psicología y Sociedad. Año II, № 2, 2019. Pág. 60-89. 
¡Vivas nos queremos!

Un análisis de sentencias sobre los femicidios de 2014 en la provincia de Córdoba

hechos de violencia se incrementaron en el último año de convivencia, culminando dicho espiral con la negación de la vida de María Justa Medina, lo que equivale a la expresión extrema de violencia de género" (Caso Orellano. Alegato del fiscal).

En este proceso llama la atención el rol de los familiares y allegados, testigos y observadores de este ciclo de violencia. En este sentido se observa que en ciertos casos estos tendían a subestimar la situación, naturalizarla; "son cosas de pareja" es la frase más ejemplificadora. Pero por otro lado se encuentran aquellos que, a pesar de su afán por "rescatar" a las mujeres de su condición de violentadas, se vieron imposibilitados de distanciar a las víctimas de sus asesinos, ya sea por la negación por parte de las misma de la situación en la que se encontraban inmersas o el miedo a recibir mayores represalias, si se rebelaban contra sus agresores.

Tras el análisis se ha observado que la gran mayoría de los que rodeaban a la víctima estaban al tanto de la situación y le aconsejaban que presente una denuncia o termine la relación con el maltratador. Aún así, lejos de comprender el ciclo de la violencia y las circunstancias que puede acarrear (temor, inseguridad, extorsión, amenazas) sus familiares y allegados parecían, según se advierte en las sentencias, poner toda la responsabilidad de la continuidad de la situación en la víctima, más específicamente en el hecho de que ella no ponía fin a la relación violenta.

A modo de ejemplos: en el caso Sosa, ante la desaparición de la víctima un familiar expresó que "desconoce dónde puede estar aunque sospecha que está con este sujeto el cual ya le ha maltratado en otras oportunidades". "La golpeaba, y L. decía que ya lo iba a dejar".

"(...) no tenés que admitir que te peguen...después yo me entero que le pegaba a ella y a su hijo... me enojé con G.... ponele límites, no tenés que dejar que le pegue a tus hijos (...) ya verán por qué se llegó a este final...". (Caso González Brites)

"había aconsejado a A. dejar a Ortega ya que el mencionado la golpeaba, perseguía, hostigaba y amenazaba" (caso Ortega).

"Ante estas dos situaciones, le dijo a P. que si quería la acompañaba a realizar las denuncias, manifestando siempre P. que M. no era capaz de hacerle nada, que no tenía coraje, que sólo quería llamar su atención."... “Que ella le dijo que hiciera la denuncia pero P. se negó por temor que le pasara algo a su hijo”... “P. se puso muy mal y llamó llorando y contándole lo sucedido, manifestándole en esa oportunidad que realizara la denuncia, la cual 
P. no terminó haciendo porque no quería tener problemas con M" (Caso Sambrenil. Testimonio de amigos de la víctima).

En realidad no se trata de que las víctimas "deseen" por una propia "irracionalidad", volver con su victimario. Concebirlas de este modo, ignorando el ciclo de la violencia, sólo lleva al eventual rechazo hacia las víctimas, no colaborando en absoluto con su protección. Como hay una vinculación emocional y afectiva fuerte, entre víctima y victimario, hay que entenderla como una relación violenta que adquiere consecuencias y matices particulares.

Inclusive los vocales hacen alusión a esta falta de salida que sienten las mujeres. Por ej. en el caso González Brites, en referencia a uno de los testimonios “quien intentó en más de una ocasión -sin éxito- que la mujer no se dejara maltratar por González Brítes", "F. intentó, pero no pudo, no supo, no encontró el modo de romper ese círculo”.

En consecuencia, para comprender el ciclo de la violencia, es necesario tener en cuenta que:

Uno de los múltiples factores que provoca la permanencia de las mujeres en relaciones abusivas es que éstas ocurren en un ciclo. Es decir, los episodios violentos no suceden a todas horas y todos los días, sino más bien se trata de episodios intermitentes. En los periodos previos al estallido violento, el agresor es considerado y se muestra arrepentido y cariñoso, lo que aumenta la confusión de las víctimas y fomenta su esperanza de un cambio definitivo. Otros factores que inciden son la dependencia económica, la carencia de redes de apoyo y la forma en que las mujeres son educadas ("es tu cruz"; "cómo voy a quitarle el padre a mis hijos e hijas"; "la preservación de la familia es responsabilidad de la mujer", "si te cela es porque te quiere”) lo cual, en ocasiones, las hace sentirse responsables o merecedoras de lo que les sucede. Esta percepción se confirma por la aprobación, tolerancia y normalización social de este tipo de violencia. (SCJN, 2015, p. 56)

A raíz de ello cabe cuestionarse si, antes de juzgarlas y de preguntarse en términos "racionales” ¿Por qué no denunció? ¿Por qué retiró la denuncia? ¿Por qué siempre vuelve con un sujeto que la maltrata? ¿Por qué no escapó o se fue del hogar?, la posible existencia de extorsión y exclusión económica, el temor, la falta de un lugar a dónde ir, los hijos en común, y muchos otros aspectos, acaso no delinean el ciclo de la violencia. Así, se evidencia que el frecuente llamado de terceros a "empoderarse y denunciar" no es tan sencillo de responder como parece. 
¡Vivas nos queremos!

Un análisis de sentencias sobre los femicidios de 2014 en la provincia de Córdoba

De hecho, llegar a denunciar ya es una manera de romper, o al menos corroer el círculo de la violencia, pero como se ha visto en los casos analizados, el maltratador continuará insistiendo de manera que, este paso, no pueda tornarse definitivo. Una mejor comprensión del ciclo de la violencia permite mostrarnos que una restricción de acercamiento sin ningún otro tipo de protección (física y psicológica) no es la solución a la problemática. Como sostiene Haimovich (1990):

No todas las mujeres van al sistema penal, porque la denuncia es vista como una ruptura definitiva, porque la denuncia supone publicidad y cuestionamiento también del mundo íntimo de la mujer, porque la denuncia supone castigo de una persona con la que aún tenemos vínculos afectivos, de la que aún confiamos en recuperar, porque añade dramatismo, porque etiqueta como delictivo lo que le está sucediendo a ella. (p.103)

En este sentido, y en relación a la situación en que muchas mujeres retiran la denuncia de violencia sería conveniente investigar a fondo los motivos por los cuales lo hacen. Posiblemente no sea sólo por características propias del ciclo de la violencia, sino también por desconfianza en torno al proceso judicial y su capacidad de respuesta.

\section{Violencia económica}

A lo largo de los siglos, y hasta la actualidad, la violencia económica ha sido una de las facetas de la violencia machista. Aunque muchas veces este rasgo ha pasado inadvertido, en las sentencias, la violencia física o psicológica ha venido también acompañada de mecanismos de extorsión económica.

Como lo indica Mabel Bianco (2015 en ELA, 2015) esta violencia puede tener lugar en dos marcos: por un lado, cuando el hombre es el proveedor o sostén económico familiar, controla y supervisa todos los gastos, llegando a amenazar a la mujer con sacarle todo, dejarla en la calle, etc. Por otro lado, "es habitual que, en casos donde la mujer es la que aporta el mayor caudal de dinero el compañero se vuelva el controlador de todo y limite su capacidad de decisión sobre ese dinero" (Bianco, 2015, p. 1 en ELA, 2015). Este proceso genera desvalorización, baja autoestima y fortalece miedos, afectando a sí a la salud física y psíquica de la mujer (Burin, 2015 en ELA, 2015).

En nuestro sistema jurídico la ley de protección integral para prevenir, sancionar y erradicar la violencia contra las mujeres entiende a la violencia económica y patrimonial

74 Debates actuales en Psicología y Sociedad. Año II, № 2, 2019. Pág. 60-89. 
como aquella "que se dirige a ocasionar un menoscabo en los recursos económicos o patrimoniales de la mujer, a través de la perturbación de la posesión, tenencia o propiedad de sus bienes, pérdida, sustracción, destrucción, retención o distracción indebida de objetos, instrumentos de trabajo, documentos personales, bienes, valores y derechos patrimoniales" (Ley $\left.\mathrm{N}^{\circ} 26.485\right)$.

En algunos de los casos analizados dicha violencia se ejerce y, en otros, es el contenido de constantes amenazas hacia las víctimas. Se observa con claridad en algunos de los testimonios que las mujeres, previo al femicidio, habían estado sometidas a violencia económica, lo cual les dificultaba romper con el mencionado ciclo de la violencia. Si bien se trata de cuestiones previas al hecho juzgado en la sentencia, dada la reiteración con la que aparecen en las mismas no resulta un dato menor (cabe mencionar que este patrón se reitera más de la mitad de los casos estudiados).

Por citar algunos ejemplos, en el caso Sambrenil sucedía "qué P. ya estaba cansada y había tomado la decisión de no perdonarlo. Que se comunicaba con M., sólo a los fines de que le devolviera el automóvil marca Duna, que si bien era de los dos, estaba a nombre de P., a lo que le ponía excusas todo el tiempo para devolvérselo, postergando su entrega."

En el caso Ortega los testimonios señalan que "le pegaba para que le diera la plata que ganaba en la ruta" "la mujer trabajaba y Ortega participaba de las ganancias" que la relación era "en parte de pareja y en parte comercial" que la misma víctima temía por sí misma puesto que el imputado la había amenazado con que si lo dejaba "le quemaría la casa”. Inclusive, en la denuncia previa la víctima refiere a un acontecimiento en el cual el imputado le quitó un teléfono celular y una suma de dinero que llevaba consigo.

De aquí que el empoderamiento femenino se torne considerablemente difícil en situaciones económicas vulnerables -incluso cuando la víctima es el principal sostén de la economía familiar-. Perla Prigoshin (2015 en ELA, 2015) indica que incluso cuando el sujeto masculino se niega a pagar la cuota alimentaria a la mujer, por los hijos que tienen en común, está ejerciendo violencia económica. Esta situación se vislumbra con claridad entre los acontecimientos que precedieron a algunos de los femicidios analizados. A saber:

"Que P. se quedó sin trabajo. (...) Que a raíz de eso fue que insistió más con la cuota alimentaria de la niña, ya que no tenía dinero para la bebé." "G. le iba a entregar el dinero de la cuota alimentaria pero finalmente no fue porque supuestamente tenía arritmia, o había chocado con un colectivo o el padre estaba internado, siempre tenía una excusa para no ir, siempre le surgía algo". "Que ella le había dicho que se iba a ir a tribunales el día jueves, a 
¡Vivas nos queremos!

Un análisis de sentencias sobre los femicidios de 2014 en la provincia de Córdoba

hacer el reclamo ante el incumplimiento de él de la cuota alimentaria (...)" (Caso Lizarralde, testimonios de familiares y amigos de la víctima).

"Sé que había un problema por la cuota alimentaria de M., mi mamá se lo pidió a M. y él la llamaba a cada rato para pedirle que no le hiciera lío en Tribunales"... "Se puso agresivo cuando se enteró que le iba a pedir cuota alimentaria" (Caso Castro. Testimonio de la familia de la víctima).

"Últimamente discutíamos, porque no le alcanzaba la plata, me dijo que había venido a Tribunales que yo le tenía que dar 500 pesos por quincena; me dijo también que yo tenía que pagar la luz y la comida; no entiendo porque tenía que darle la plata a ella" (Caso Quevedo. Testimonios del imputado).

\section{Victimización del imputado e insistencia por retomar la relación}

Un aspecto visible, en casi en la totalidad de las sentenciases, es que las víctimas habían tomado coraje para poner fin a la relación con el imputado. Los victimarios no aceptaron esta realidad e insistieron a través de diversos medios (mensajes, llamados, acoso en su domicilio o en la vía pública, búsqueda de información acerca de la víctima en su trabajo o consulta a sus allegados) para retomar la relación.

Dicha insistencia va de la mano con intentos de disculparse y mostrar 'arrepentimiento' por lo acontecido, buscando generar sentimientos de compasión en la víctima para que deshaga su decisión. Aquí se ve claramente la fase "luna de miel” del ciclo de la violencia en la cual el hombre se disculpa de sus actos y se humilla a sí mismo ante la posibilidad de perder a la mujer objeto de su posesión.

Para citar algunos ejemplos: "constantemente le mandaba mensajes de texto, pidiéndole perdón, que no iba a pasar de nuevo, que volviera con él, que si ella no regresaba él no tenía vida y se iba a morir" (caso Sosa),

“Así, es que la primera vez que M. engaño a su hermana y se fue a vivir a Huinca Renancó, el papá de aquél (...) le dio plata para que le comprara las alianzas de casamiento, regresando a Río Cuarto, pidiéndole perdón a su hermana y le propuso casamiento (...) Que al avanzar la relación, con tantas idas y vueltas, al último $P$. ya no confiaba en M., pero siempre lo perdonaba porque él se ponía muy mal y volvía llorando y diciéndole que la amaba, que no podía vivir sin ella" . (Caso Sambrenil. Testimonio de la hermana de la víctima) 
"él le pegó una trompada acá en la mejilla (...) le mandaba mensajes diciendo te amo, te extraño (...)" (Caso Sosa).

"le insistió que no iba a volver a pasar, que él iba a cambiar, y que volviera con él, a lo que ella se había negado y se lo había dejado en claro”... "G. compraba el diario y le buscaba dónde vivir" (caso González Brites). Esto incluso puede verse en algunas de las denuncias previas de las víctimas, por ejemplo G. F. quien tras mencionar que por decisión de ambos están conviviendo aduce "él no tiene a nadie, me da lástima (...) y aporta económicamente al sostenimiento familiar (...)” (caso González Brites).

Al observar este contexto, donde se evidencia dicho ciclo, es posible comprender una de las razones por las cuales las mujeres víctimas retiraban las denuncias, en lugar de juzgarlas por ello. Entre más pasaba el tiempo y las mujeres mantenían su decisión (signo de empoderamiento) más tensa se volvía la relación "(...) estaban separados y no se iba, él recién se va cuando G. puso un abogado...hacía un mes y medio antes del hecho 5 ", (caso González Brites). "Quería que volviera con él y que le había dicho que no, de ninguna manera, esto fue una semana antes del hecho"(caso Sosa). Las víctimas le habían manifestado con claridad a sus allegados que no querían estar más con esa pareja. Su decisión era firme.

La contracara de este empoderamiento fueron amenazas, con el consiguiente efecto de miedo y sensación de vulnerabilidad por parte de las víctimas, tal como lo reseñan los testimonios: "A F. se la notaba atemorizada, que temía por la reacción que O.D. pudiera tener frente al rompimiento de la pareja” (caso Ortega) "ella le tenía miedo...la violencia venía de antes" (caso González Brites) "L. le tenía miedo a M.” (caso Sosa) o las mismas denuncias previas de las víctimas, que tiene mucho miedo de que se repita lo antes narrado, que teme por sus hijos y por ella misma, ya que Ortega es muy impulsivo." (Caso Ortega).

\section{Cosificación de la mujer}

Una de las categorías que podría considerarse como central es la cosificación de la mujer. Esta categoría surgió durante el análisis debido al constaste menoscabo que sufrían las víctimas en sus relaciones con los victimarios. El no ser consideradas personas plenas, la humillación, la actitud "posesiva" de los hombres o el simple menosprecio denotan esta consideración de las víctimas como mujeres-objeto.

\footnotetext{
${ }^{5}$ Las negritas son nuestras.
} 
¡Vivas nos queremos!

Un análisis de sentencias sobre los femicidios de 2014 en la provincia de Córdoba

Se establece de esta manera que existe, en palabras de Alonso (2015),

"una íntima relación entre los estereotipos y los círculos de violencia: mujeres subordinadas, estigmatizadas por su desarrollo sexual, mujeres cosificadas, ausencia de empoderamiento, derechos conculcados, son alguna de las tantas manifestaciones. Estos estereotipos son reproducidos y alimentados principalmente por los medios de comunicación. (...) La cosificación en los programas de mayor rating que por las noches miran las familias argentinas, siguen reproduciendo a la mujer como un elemento sexual subordinada al poderío masculino” (p. 153)

Estos rasgos en las sentencias se visualizan en los testimonios. Es frecuente que estas actitudes cosificadoras se desprendan ante la posibilidad de que la mujer (concebida por el hombre como objeto de su posesión) lo engañe o deje e inicie una nueva relación, o bien que no se amolde a las expectativas de vida y deseos del victimario. Retomamos algunos ejemplos:

"huy mi amor, cierto que no puedo decir nada (...) el estúpido este dice que me va a matar si lo gorreo o lo dejo, y él le dice hacete la viva, ya vas a ver (...) Que le decía que si se enteraba la mataba, no quería que se juntara con nadie", "seguro que él se enteró que había conocido a ese chico porque la seguía a todas partes", a ciertas reuniones "ella nunca iba, y le comentan que era porque él no la dejaba (...) al solo efecto de que no tuviera contacto con los otros hombres que trabajaban allí (...) deduce que M. era una persona muy celosa con su esposa", "no quería que trabajara de noche" , "él quería que tuvieran un hijo, M. estaba obsesionado y ella no quería tener un hijo con él” (caso Sosa).

"Iba a su trabajo a buscar información de ella" "se bajó del auto con un cuchillo en la cintura y la amenazó con el mismo y él dijo "si no sos mía no sos de nadie" (Caso Sambrenil) .

"Cuando volvió P., era como que a G. no le gustó que ella se hubiera ido de vacaciones y no se hablaban" "Comentó a modo de chiste, que si le pasaba a él lo mismo (tener un hijo no querido) la cargaba y la tiraba a la mujer al dique" (caso Lizarralde)

"Éste le contó que estaba mal porque la M. lo había echado, pero que no se iba a ir porque si no la tenía él a la M. no la iba a tener nadie” (caso Orellano). 
"Muchas veces cuando él discutía con ella por temas de celos la ha amenazado, le decía palabras como "si no estás conmigo no vas a estar con nadie, si hace falta que te mate, te voy a matar" (Caso Castro).

Esta categoría emerge también de las denuncias previas de la víctima. Si bien para llevar a cabo un análisis exhaustivo de las denuncias se requiere tener acceso a los expedientes judiciales, cuando se retoman sus argumentos en la sentencias por el femicidio, es evidente la actitud posesiva y controladora del imputado. Se presentan amenazas del tipo "si me dejas te quemo la casa", "le dijo que no la dejaría en paz, y se llegaría al lugar donde se encuentre trabajando, como así también que no tiene problemas para enfrentar a la policía y trenzarse en lucha con los mismos." (Fragmentos del caso Ortega).

Incluso, algunos de los victimarios ejercían violencia física sobre otros sujetos distintos a la víctima, como sus ex parejas (caso Ortega) o hijos (caso González Brites). Prestar atención a estos comportamientos, en las denuncias previas, puede ser útil para prevenir desenlaces como los observados.

En relación con esta categoría, cabe mencionar que si bien estos testimonios son sumamente ricos para el presente análisis, no en todos los casos se les otorga su real trascendencia a la hora de fundamentar los fallos.

\section{Desencadenantes del femicidio - Empoderamiento de la víctima}

Es importante analizar los factores que desencadenan el femicidio, pues en ellos se visualizan los roles de género y la sobreviniente cosificación de la mujer. En la mayoría de los casos, lo que desencadena el hecho es que la víctima posea nuevo sostén económico (independiente del imputado), una nueva -o posible nueva- relación amorosa o tome la decisión de poner fin a la relación con el imputado. En otras palabras, los femicidios se producen luego de la transformación de la mujer-objeto en la mujer empoderada o mujersujeto.

Es a partir de allí que cobran relevancia los estereotipos de género, y las consecuencias que trae para las mujeres el "no encajar" en los mismos. En palabras de Silvia Andrea Alonso (2015):

se considera, que la mujer que debe estar en su hogar, cuidar de su marido e hijos, limpiar, planchar, hacer las compras y cuidar del bienestar de su familia. Pendiente de su esposo, quien le proveerá bienestar económico, en el que encontrará 
¡Vivas nos queremos!

Un análisis de sentencias sobre los femicidios de 2014 en la provincia de Córdoba

y buscará protección. Ello conlleva a emparentar al sexo femenino con la debilidad y subordinación económica. Por el contrario el hombre, ha sido conceptualizado como la fuerza, la rudeza, el sostén de familia y la virilidad, el que da batalla en las guerras. Este hombre no plancha, no lava, no cocina, impone su voluntad sobre el de su pareja, decide de todo y acerca de todo, en definitiva el hombre con superioridad en todo sentido. Estos estereotipos producen y reproducen la subordinación en todos los planos que durante años padece y padeció la mujer. La construcción de los roles de este modo, son los que generan, junto con otros factores, la violencia contra la mujer en todos los planos (p. 151).

Es en este sentido que cuando parece entrar en declive la relación tradicional de dominio sobre la mujer por parte del hombre (que en muchos casos llevaba años) se producen los femicidios, con el objetivo de evitar la emergencia del empoderamiento femenino, el cual los femicidas no pueden soportar. En todos los casos se observa que el hecho desencadenante no es más que un suceso que evidencia un empoderamiento por parte de las mujeres que resquebraja los esquemas patriarcales. Esto sucede cuando las mujeres adquieren decisión sobre su cuerpo, sexualidad o relaciones afectivas, intentan independizarse económicamente, poniendo en cuestión la supremacía del hombre en la relación y negándose a cumplir el rol de mujer-esposa, mujer-madre, mujer-sirviente, mujer-amante, y en fin... mujer objeto.

A continuación se enuncian algunos de los hechos desencadenantes de los femicidios analizados: la víctima asistió a un evento social sin él (caso Barrionuevo), reclamó la identidad de su hija y la cuota alimentaria correspondiente -los mismos jueces indicaron que "se trataba de una mujer que "no fue dócil" a la postura que asumió Lizarralde (sobre su paternidad), sino que decidió empoderarse en defensa de sus derechos y los de su hija"(caso Lizarralde); "dejó de trabajar en el remis, que era de propiedad de M., pero se mantenía con plata que H. le daba”, "ella no quería saber más nada con M." (Caso Sosa); el imputado previo al hecho “insulta a $N$. y le recrimina 'puta te fuiste con otro', 'yo sabía que me ibas a engañar con ese'" (caso Ortega).

En relación al caso Sambrenil, el tribunal sostuvo: "Lo cierto es que, tal como en las anteriores oportunidades, el hombre comenzó a reclamar para retomar el vínculo, encontrándose esta vez con la firme negativa (de la víctima) (...) Y es este el punto medular que desencadena el desborde y la violencia. No cabe duda alguna que fue el despecho, la imposibilidad de obtener lo que quería, lo que motivó las conductas de Sambrenil quien, durante ese mes, amenazó y hostigó a la mujer". 
En el caso González Brites, la discusión previa al femicidio se produce porque la víctima, tras haber puesto fin a la relación, le solicita al imputado que retire el auto que había dejado en el garaje de su vivienda para poder alquilarlo, con lo cual el victimario se siente desplazado de su antiguo hogar. La víctima le quita lo que "es suyo" para que sea "utilizado por otro”: “¿Para qué querés que saque el auto, para que venga tu macho y ponga otro? (...) No, le dice mi mamá, lo voy a alquilar, necesito alquilar porque la plata no me alcanza (...) No, sí tenés otro macho, le querés poner el auto al otro macho (...)” (Caso González Brites, testimonio de la hija de la víctima).

A fin de cuentas, esta cosificación no es más que el reflejo de los diferentes comportamientos sexuales y sociales, cultural y diferencialmente exigidos a cada género, y la necesidad de que la mujer se ajuste al estereotipo de sumisa/obediente/casta. Si no lo hace, los victimarios no pueden tolerar esta "rebeldía" de su pareja o ex pareja a los imperativos sociales, no soportan dejar de poseer a la mujer, que conciben como objeto, y terminan cruentamente con su vida.

\section{Envilecimiento /deificación de la víctima}

En relación a la víctima se crean, perpetúan y mantienen estereotipos sobre las mujeres que pueden incidir en el ejercicio profesional de los operadores de justicia implicados. En lo que hace al envilecimiento de la misma, éste se presenta cuando las características de la víctima hacen que sea considerada como propiciatoria o merecedora de lo ocurrido. Se piensa que determinados crímenes sólo les ocurren a ciertas personas que llevan modos de vida diferentes, que pertenecen a determinados grupos étnicos, que tienen ciertas creencias religiosas, que son de algunos grupos sociales, que tienen nivel económico bajo, que consumen drogas, que exteriorizan una orientación sexual distinta, etc. (Turvey, 1999 en OACNUDH y ONU Mujeres, 2014).

Como se menciona anteriormente, el ser mujer facilita que el contexto de los crímenes se construya sobre estereotipos culturales dada su posición de subordinación en la sociedad. (Turvey, 1999 en OACNUDH y ONU Mujeres, 2014). Incluso, “responsabilizar a la víctima y su familia por su estilo de vida, por la ropa que usan, por el horario en el que suelen estar en la calle o por su conducta sexual previa, son algunas de las cuestiones que quebrantan la dignidad de la víctima, se inmiscuyen en su intimidad, y tienen el efecto de revictimizarlas"(Asensio, 2010, p. 91)

Algunos ejemplos de este envilecimiento o revictimización:

81 Debates actuales en Psicología y Sociedad. Año II, № 2, 2019. Pág. 60-89. 
¡Vivas nos queremos!

Un análisis de sentencias sobre los femicidios de 2014 en la provincia de Córdoba

"Se pelearon porque ella le contó que estaba saliendo con tres tipos más" (caso Aragallo).

"ella era celosa, ambivalente (lo buscaba y echaba), controladora, sofocante, violenta con su hija, depresiva”, "ella era manipuladora, de carácter fuerte, él no era celoso, ella lo cansó" "Ella era muy celosa, no me dejaba vivir. Ella me decía "si vos me dejas, me voy a matar", "Ellos siempre discutían, el fondo de todo eran los celos de ella hacia mi papá." (Caso Castro, testimonios del imputado y sus familiares).

"M. estaba enamorado de L., pero ella era una chica que le gustaba vivir la vida, salir, divertirse, salir de caravana, y cuando le pintaba una relación con algún chico no tenía problema en concretar una salida, y así fue como conoció a M., y sabe que mientras estaba con M. también tenía otras relaciones con otras personas" "era una mujer de carácter, de carácter fuerte, no era de ser manejada" "ella salía con uno, con otro (...) era una loca linda, divertida". (Caso Sosa, testimonios de amigos de la pareja).

"Yo tenía que hacer la comida porque últimamente no cocinaba; (...) Ella salía mucho últimamente, a los bailes se iba, no quería salir conmigo, (...) Ella empezó a cambiar últimamente, ella me dijo que se iba a ir de la casa" (Caso Quevedo, testimonio del imputado).

Como se evidencia, los rasgos que se pueden atribuir a una mujer empoderada son presentados como negativos, y rige un ideal estereotipado de mujer que condiciona su carácter, horizontes y sexualidad. Incluso a veces, los rasgos asociados a la sumisión son vistos como positivos: "ella se pintaba y salía, se ponía los anteojos para que no se vean los golpes...no decía nada...era muy buena" (caso González Brites, testimonio de una amiga de la víctima).

En consecuencia, la víctima es juzgada por desobediente, por mala madre, por "puta", por mala esposa o pareja. Estas categorías implican una ruptura con el estereotipo hegemónico de mujer ideal, siendo ésta desobediencia la que tiene por consecuencia primero la violencia verbal, física, psicológica y económica, concluyendo por último en el femicidio, como castigo obligado ante tales actos de rebeldía.

En lo que respecta a la "deificación de la víctima", ésta hace referencia a su idealización. La víctima pasa a ser valorada por algunas de sus circunstancias vitales, como por ejemplo ser joven, pertenecer a una familia de status elevado, estar estudiando en la universidad, etc. (Turvey, 1999 en OACNUDH y ONU Mujeres, 2014), En los casos

82 Debates actuales en Psicología y Sociedad. Año II, № 2, 2019. Pág. 60-89. 
analizados hemos observado que en las características positivas o deificadoras atribuidas a las víctimas hay una primacía de atributos vinculados a la maternidad, v.g: "era muy madraza, nunca hubiera dejado solos a sus hijos" "consumía cocaina (...) no obstante siempre fue una buena madre” (caso Sosa), "era una madraza, a los chicos nunca les faltaba nada, estaban felices de estar con ella" (caso Lizarralde) "se hacía cargo ella del bebé, lo quería bastante y mucho”, "a todos los alimentaba (...) alquilaba la casa y pagaba el alquiler" (caso Aragallo).

La mujer es definida o descripta como "madre en primer lugar". En referencia a ello, cabe indicar que la teoría feminista ha demostrado que el imaginario social sobre la maternidad está configurado por diversas representaciones que identifican la maternidad con lo femenino proporcionando un ideal común para todas las mujeres. En el discurso hegemónico, la maternidad ha sido presentada como un estereotipo unificador de las mujeres, rechazando las individualidades y elementos tales como la clase social o el nivel cultura (Saletti Cuesta, 2008). Si bien por las características del sistema patriarcal no resulta sorprendente la asociación entre las etiquetas "mujer" y "madre", “mujer” y "hogar", sí es llamativa la cantidad de veces que las mismas se reiteran y reproducen en las sentencias.

\section{Deificación y envilecimiento del imputado}

Aunque Turvey (1999 en OACNUDH y ONU Mujeres, 2014) construye los conceptos de deificación y envilecimiento para referirse a la situación de la víctima, sin embargo, se considera que los mismos son también aplicables al victimario.

Así, uno de los patrones que se puede encontrar en las sentencias es una autodeificación por parte del imputado, lo cual no es de extrañar puesto que trata de defenderse en el juicio. Algunos ejemplos:

"Tuve ese error en la vida (...) nunca había sido agresivo (...) a lo mejor lo hice porque la amaba mucho, estoy arrepentido..." (Caso Sambrenil), "Yo ya venía durmiendo en el suelo porque ella no me aceptaba, decía que era poco hombre para ella” (Caso Quevedo). "Pido disculpas, pido por mis tres hijos... actué en legítima defensa, era mi vida o la de ella, tuve que defenderme, pido una oportunidad para poder criar a mis hijos y demostrar la persona que soy" (caso González Brites).

Asimismo, esta deificación también se manifiesta en amigos, familiares y entorno del imputado (muchos de ellos conscientes de que el mismo ejercía violencia contra su pareja o ex pareja). Algunos ejemplos: “G. (...) fue criado con ciertos principios”, "no era una 
¡Vivas nos queremos!

Un análisis de sentencias sobre los femicidios de 2014 en la provincia de Córdoba

persona celosa (...) siempre fue muy tranquilo", "es una persona de bien” (caso Lizarralde). "Él siempre fue muy tranquilo, no era agresivo; él es un hombre de poco carácter, lo contrario de ella; tenía poco carácter para mandar, ella mandaba más” (caso Quevedo). "Es alegre, amable, de buen carácter, solidario", "una persona tranquila, caradura, divertido" (caso Sambrenil). "Era una persona tranquila, sin problemas y calmo" (caso Sosa). "Se las rebuscaba como remisero, que tuvo vehículos a cargo (...) él estaba enamorado de L." (Caso Sosa, defensa del victimario).

Y en relación con el envilecimiento del imputado prácticamente no se hace presente en las sentencias. Frente a esta situación cabe abrir el interrogante: ¿Es esto una mera casualidad? O bien ¿Cuál es el trasfondo socio-cultural que da lugar a que el envilecimiento, tras un femicidio, sea sólo de la víctima?

\section{Lo que dejan los femicidios}

En sí mismo la muerte de una persona a manos de otra trae aparejado consecuencias nefastas y produce efectos violentos a largo plazo, tanto en el núcleo familiar como en la sociedad en general. En el femicidio no sólo son protagonistas la víctima y el victimario, sino que los efectos se resienten en todo el contexto que los rodea: familiares, amigos y allegados que quedan marcados de por vida por estos hechos violentos. Especialmente afectados resultan los hijos e hijas de las víctimas, siendo que en la mayoría de los casos el padre es el propio victimario, sumado a que generalmente son menores de edad. Estos niños y niñas no solo terminan siendo criados fuera de su seno familiar, sino que además suelen ser testigos presenciales de la muerte de su madre, y se deduce que probablemente han estado expuestos a situaciones de violencia familiar constantes que pueden tener secuelas para el resto de sus vidas.

"La hija de N. lloraba y expresaba "el Cheli la mató” (caso Ortega).

"Que hasta que la trasladaron al Hospital Córdoba, su madre le decía "no me dejes morir, cuídalo al E. (refiriendo al hijo de la víctima)", "Que E. está viviendo con ellos, que les pidió si podía decirles mamá a N. y papá a él porque él ya no tiene mamá ni papá porque el Pila la mató. Que una noche se despertó muy asustado y llorando decía "ahí está el Pila en la ventana nos va a venir a matar, cuidala, cuidala a esta mamá”. Que E. piensa que es culpa suya porque no pudo ayudar a su mamá." 
“Licenciada: ¿qué le pasó a la mamá? -Menor: estaba peleando con mi papá y mi papá agarró el cuchillo y le metió -Licenciada: y ¿cómo sabes eso vos? -Menor: porque vi... -Licenciada: ¿dónde estabas vos? -Menor: estaba ahí viendo”(Caso Orellano. Testimonio de la hija y yerno de la víctima. Cámara Gesell realizada al menor.)

Quizá uno de los más impactantes, aunque todos estos casos resultan sensibilizadores y adquieren sus particularidades, fue la situación vivida por la hija de Paola Acosta, quien "permaneció durante tres días herida, dolorida, al lado del cuerpo de su madre muerta, aferrada a esas ropas frías, en la oscuridad, sin comida ni bebida, sintiendo durante dos noches la caída de la lluvia que se escurría hacia ese lugar y la mojaba. Es impredecible el daño psicológico futuro que podría afrontar esta niña cuando conozca la calamidad a la que la sometió su padre biológico” (Caso Lizarralde, declaración de uno de los vocales).

Es menester preguntarse si los mecanismos de protección disponibles hacia los niños y niñas que viven en estos entornos son suficientes y aseguran el necesario acompañamiento a los mismos. A su vez, los femicidios, además de dejar por el lado de las víctimas vidas truncas, sueños y anhelos que quedan en el camino, dejan también familias destrozadas.

\section{Discusiones finales}

En el presente trabajo se han abordado y desarrollado diversas categorías, construidas a partir de las lecturas de las sentencias, con el fin último de comprender y analizar el fenómeno de femicidio. En este sentido, los fragmentos extraídos de las mismas han sido más que ejemplificadores y esclarecedores de lo que sucede en la sociedad, pero aun así es necesario aclarar que lo que se trasluce de esta realidad en las sentencias, por impactante que sea, es sólo una mínima porción de la misma.

En esta línea, es necesario hacer énfasis en que la relevancia del presente análisis reside en la transversalidad que las categorías adquieren, las cuales devienen directamente de la configuración de una sociedad de carácter androcéntrica y patriarcal, donde están determinados los roles de género y el cuestionamiento de estos mandatos sociales son castigados con la represión y violencia directa.

El androcentrismo corre aún por las venas de la cultura actual, se transmite en los procesos de socialización y ningún sector de la sociedad está exento. Esto se ha evidenciado de manera clara en el análisis de casos que han culminado con el arrebato de la vida de las víctimas, pero no se debe dejar de lado que, también en la cotidianeidad, se está rodeado de 
estereotipos de género y micromachismos naturalizados y arraigados en el imaginario colectivo; los cuales acarrean consecuencias nocivas para el empoderamiento femenino.

Otro aspecto, que el análisis posibilita señalar, reside en si existe la necesidad de poner más herramientas a disposición del círculo de allegados de la víctima y enfatizar más su rol en las campañas comunicacionales que buscan prevenir la violencia contra las mujeres. A raíz de ello surge la siguiente reflexión: ¿se debe dejar solamente en manos de la víctima la posibilidad de iniciar y finalizar el proceso? Hay posturas que entienden que sí, puesto que brindar herramientas a terceros atentaría contra su autonomía. No obstante, es difícil que la mujer, por el propio marco relacional en el que se produce la violencia, reconozca su situación. ¿Es esto, entonces, la mejor salida y resguardo para la víctima?

Poner fin al ciclo de la violencia siempre pareciera quedar en manos de la mujer, sin importar su condición de vulnerabilidad. La víctima carga con la responsabilidad de autoprotegerse acudiendo al sistema penal por cuenta propia. En su entorno muchos son testigos de la violencia reiterada y, a fin de cuentas, la única salida está en la mujer/víctima. ¿Esto es un vicio del sistema judicial, de las campañas de prevención de la violencia que depositan continuamente la solución en la víctima o una inacción de la sociedad, del entorno de cada una de las víctimas? ¿Es favorable no tomar papel y resguardar su autonomía aun en estos casos? ¿O acaso todo esto es meramente consecuencia de una falta de conocimiento del ciclo de la violencia por parte de la sociedad?

Todos estos aspectos llevan a pensar no sólo en torno a las medidas judiciales sino también a otras políticas, como por ejemplo el botón anti-pánico. Un desconocimiento de las particularidades del ciclo de violencia en el que viven inmersas, indudablemente, dificulta que el poder judicial responda con debida diligencia, y consiga evitar estos lamentables desenlaces. Buena parte de las víctimas habían acudido previamente a la justicia pero incluso con ello no obtuvieron la suficiente protección y contención.

En este sentido se señala que el reconocimiento del ciclo de violencia por parte de la víctima, el hacerse consciente de su situación, es el primer paso para romper con el mismo y pedir ayuda. No obstante, por las características que posee la dinámica de ese ciclo este reconocimiento puede tornarse muy difícil y, por tanto, poco plausible. Por ello, si el objetivo es realmente combatir este fenómeno, probablemente sería aconsejable poner mecanismos para evitarlo o detenerlo en manos de alguien externo al ciclo, por ejemplo familiares y allegados. Actualmente en sistema judicial argentino no existe esa posibilidad. Caso contrario, 
no se deja de entender a la violencia como un fenómeno intrafamiliar en el que el Estado no debe inmiscuirse salvo pedido expreso de las partes involucradas.

En este contexto, pareciera que el derecho puede ser comprendido como un dispositivo de poder en sentido foucaultiano, es decir, debería analizarse en su contexto de actuación. En otras palabras, el discurso jurídico no se gestaría en una cápsula aislada del orden social en el que tiene lugar, y por ello carecería de la pretendida objetividad, neutralidad y universalidad que se arroga. En consecuencia, no se descarta su potencial como herramienta de transformación social.

\section{Referencias Bibliográficas}

Aguilar, A. (2005). Femicidio: La pena capital por ser mujer. Revista Diálogos. Nueva Época. 4(44). Recuperado de http://www.sidocfeminista.org/images/books/12946/12946_00.pdf

Alonso, S. (2015). Género, estereotipos y violencia contra la mujer. Revista Jurídica DoCesuca, 3 (6). Recuperado de http://ojs.cesuca.edu.br/index.php/revistajuridica/article/view/1059

Asensio, R. (2010). Discriminación de Género en las Decisiones Judiciales: Justicia Penal y Violencia de Género. Buenos Aires: Defensoría General de la Nación. Recuperado de http://www.mpd.gov.ar/pdf/publicaciones/biblioteca/010\%20Discriminacion\%20de\% 20Genero\%20en\%201as\%20Decisiones\%20Judiciales.pdf

Bobbio, N. (1994). Teoría General del Derecho. Bogotá: Editorial Temis.

Butler, J. (2001). El género en disputa: el feminismo y la subversión de la identidad. México: Paidós. Recuperado de http://www.mnba.cl/617/articles-8672_archivo_01.pdf

Buompadre, J. E. (2013). Los delitos de género en la reforma penal (Ley 26.791). Revista pensamiento penal, (152), 1-43. Recuperado de http://www.pensamientopenal.com.ar/system/files/2013/02/doctrina35445.pdfhttp://w ww.pensamientopenal.com.ar/system/files/2013/02/doctrina35445.pdf

Censori, L. (2016). Feminismo y derecho penal. Revista pensamiento penal. Recuperado de http://www.pensamientopenal.com.ar/system/files/2016/04/doctrina43270.pdf

Corte Suprema de Justicia de la Nación. República Argentina. (2015). Registro Nacional de Femicidios de la Justicia Argentina. Datos estadísticos del Poder Judicial sobre: Femicidios 2015. Recuperado de http://www.csjn.gov.ar/om/docs/femicidios_2015.pdf 
ELA. (2015) Violencia contra la mujer: cuando el abuso es económico. Recuperado de http://www.ela.org.ar/a2/index.cfm?fuseaction=MUESTRA\&codcontenido=2347\&plc ontampl $=38 \&$ aplicacion $=$ app $187 \& \mathrm{cnl}=36 \&$ opc $=50$

Foucault, M. (1975). Vigilar y castigar. Recuperado de http://www.uruguaypiensa.org.uy/imgnoticias/592.pdfhttp://www.uruguaypiensa.org.u y/imgnoticias/592.pdf

Foucault, M. (1979). La microfísica del poder. Recuperado de http://www.pensamientopenal.com.ar/system/files/2014/12/doctrina39453.pdf

Fragoso Monárrez, J. (2000). La cultura del feminicidio en Ciudad Juárez, 1993-1999. Frontera $\quad$ Norte, $\quad 12$ (23). https://www.redalyc.org/pdf/136/13602304.pdf

Gargallo, F. (2012). Tan derechas y tan humanas. Manual ético de derechos humanos de las mujeres. Recuperado de http://francescagargallo.wordpress.com/ensayos/librosdefg/tan-derechas-y-tanhumanas

Gobierno de México. (2016). Comprender el círculo de la violencia es el primer paso para romperlo. Recuperado de https://www.gob.mx/mujeressinviolencia/articulos/comprender-el-circulo-de-laviolencia-es-el-primer-paso-para-romperlo

Haimovich, P. (1990). El concepto de malos tratos. Ideología y representaciones sociales. En V. Maquierira y C. Sanchez (comp). Violencia y Sociedad Patriarcal. Madrid: Pablo Iglesias.

La Nación. (3 de junio de 2015). Cómo detectar casos de violencia de género y qué hacer. Recuperado de http://www.lanacion.com.ar/1798353-como-detectar-casos-deviolencia-de-genero-y-que-hacer

Ley 26.485 (2009) Ley de protección integral a las mujeres. Recuperado de http://servicios.infoleg.gob.ar/infolegInternet/anexos/150000-

154999/152155/norma.htm

Oficina Regional para América Central del Alto Comisionado de las Naciones Unidas para los Derechos Humanos (OACNUDH) y ONU mujeres (2014). Protocolo Latinoamericano de Investigación de Femicidio (PLIF). Recuperado de http://www.ohchr.org/Documents/Issues/Women/WRGS/ProtocoloLatinoamericanoD eInvestigacion.pdf 
Suprema Corte de Justicia de la Nación. (2015). Protocolo para juzgar con perspectiva de género haciendo realidad el derecho a la igualdad. México D.F.

Van Dijk, T. (1994). Discurso, poder y cognición social. Cuadernos, 2(2). Recuperado de http://www.discursos.org/Art/Discurso,\%20poder\%20y\%20cognici\%F3n\%20social.pd $\underline{\mathrm{f}}$

Van Dijk, T. (1999). Ideología. Una aproximación multidisciplinaria. Barcelona: Gedisa.

Van Dijk, T. (2004). Discurso y Dominación. Bogotá: Universidad Nacional de Colombia. Facultad de Ciencia Humanas. (Grandes Conferencias en la Facultad de Ciencias Humanas, 4). Recuperado de http://www.discursos.org/oldarticles/Discurso\%20y\%20dominaci\%F3n.pdf

Vélez Bautista, G. (2008). La construcción social del sujeto político femenino. Un enfoque identitario subjetivo. México: Universidad Autónoma del Estado de México. Facultad de Ciencias Políticas y Administración Pública. 